\title{
RESTAURANT REVENUE MANAGEMENT: COULD IT WORK?
}

\author{
Sheryl E. Kimes \\ Cornell University \\ School of Hotel Administration
}

243 Statler Hall

Ithaca, New York 14853

sek6@cornell.edu

In general, companies using revenue management forecast by the inventory unit they sell, the time interval they sell it for and the price they charge for it. Forecasting in most restaurants is fairly rudimentary, and generally the only forecasts made is the daily number of covers (customers). In order to be able truly to manage customer arrivals, restaurants should first develop detailed forecasts of customer arrivals by hour and party size. Restaurants are not quite ready to forecast by length of stay, because it is not typical to ask how long guests will need the table, but if the restaurant is able to reduce the variation in it dining times, it can roughly determine how long people will stay at the table.

KEYWORDS: business forecasts, restaurants, financial managements, reservations 


\section{INTRODUCTION}

Reservation-based restaurants have two streams of demand: reservation requests and walk-ins. Reservation requests are most frequently taken at the restaurant, although computerised (RsVIP and JTech) and online reservation systems (open table.-com, iseatz.com and dinnerbroker.com) arc available, while walk-ins are typically managed by the restaurant host or hostess, although some restaurants use the on-site and online reservation systems to help manage walk-ins.

Restaurants that take reservations have several decisions to make

(1) the expected number of reservations and walk-ins

(2) the number of different-sized tables should be available at different times

(3) the types of restrictions (such as party size or maximum dining duration) that should be used

(4) the number of tables to set aside for potential walk-ins or for VIP customers

(5) the overbooking level.

These questions are very similar to those that have been faced by the hotel, airline and rental car industries for years. This paper discusses how revenue management techniques and strategies can be applied to the reservation-based restaurants, and potential areas for future research are discussed.

\section{FORECASTING}


In general, companies using revenue management forecast by the inventory unit they sell, the time interval they sell it for and the price they charge for it. For example, hotels forecast by rate category and length of stay for each arrival day, and airlines forecast by fare bucket, and in some cases origindestination pair.

Forecasting at most restaurants is fairly rudimentary, and generally the only forecast made is for the daily number of covers (customers). In order to be able truly to manage customer arrivals, restaurants should first develop detailed forecasts of customer arrivals by hour and party size. Restaurants are not quite ready to forecast by length of stay, because it is not typical to ask how long guests will need the table, but if the restaurant is able to reduce the variation in its dining time, it can roughly determine how long people will stay at the table.

Obtaining the unconstrained demand data is problematic because, like most hotels and airlines, restaurants do not track turned-down reservation requests or the number of walk-ins that are turned away. In addition, other potential customers may not even attempt to make a reservation or go to the restaurant because they may assume that they will not be able to get a table. Hotels and airlines have faced similar challenges and have had to develop methods for estimating their unconstrained demand either by tracking their denials and regrets or mathematically estimating their unconstrained demand.

\section{ALLOCATIONS}

At the same time, restaurants must decide how many reservations to take by time period. This decision not only includes the number of tables, but also the size of each table. For example, it may decide to allot four 6-tops (tables for six), ten 4-tops (tables for four) and ten 2-tops (tables for two) for 
each hour. Or, it may decide to have variable allocations by time period. The allocation decision is affected by staffing levels, the dining duration and the expected amount of walk-in business. Obviously, the table mix of the restaurant affects this, and a restaurant with a suboptimal table mix will operate in a less profitable fashion. While research on the optimal table mix has been conducted, little research has been conducted on how to determine the optimal table allocation.

\section{RESTRICTIONS}

Like hotels and rental car companies, restaurants could put restrictions on reservations. For example, hotels and rental car companies may use length of rental requirements and airlines may use Saturday night stay and pre-pay restrictions. Length of stay restrictions are typically not used by restaurants because of the possible impact on customer satisfaction, but restaurants could put restrictions on party size. For example, restaurants could decide that the minimum party size for a 4-top was four, or the minimum party size tor a 6-top was six. Such a policy would help increase both seat occupancy and revenue. If restaurants had a good forecast, they could use optimisation methods to determine what these restrictions should be.

\section{PROTECTION LEVELS}

Airlines typically set aside a certain number of scats for full fare customers, and hotels set aside a certain number of rooms for rack rate customers. Restaurants have two similar problems: the number to set aside for important customers and the number of tables to set aside for walk-in business. For 
example, restaurants in casino hotels would prefer to seat high-spending gamblers (high rollers) than low-spending customers. They need to decide how many tables to set aside for these high-spending gamblers while still making sure that they have tables available for other customers. Similarly, restaurants need to make sure that they have sufficient tables set aside for walk-in customers. The EMSR models typically used in the airline industry could be applied to this problem.

\section{OVERBOOKING}

Like most capacity-constrained businesses, restaurants have a problem with no-shows. Airlines, hotels and rental car companies use overbooking to help compensate for potential no-shows, and restaurants could follow a similar practice. Displaced customers in the airline and hotel industries typically have to be compensated (generally by giving them a free flight or free room), but in restaurants, displaced customers usually just have to wait to be seated. Airline and hotel overbooking models could be easily applied to restaurants to help determine appropriate overbooking levels.

\section{RESEARCH DIRECTIONS}

The restaurant industry is about three times as large as the hotel industry. Revenue management has been shown to increase revenue by 3-5 per cent in the hotel, rental car and airline industries. If common revenue management techniques could be applied to restaurants, similar revenue increases could be achieved. The challenge for researchers and managers is to develop and implement the methods necessary to make the translation. 
First and foremost, better forecasting methods for restaurants need to be developed. Ideally, forecasts should be developed by time period (hour) and party size. Forecasting methods that have been developed for the hotel and airline industry could be applied to the restaurant industry. secondly, allocation methods should be adapted to help restaurants not only determine how many different-sized tables to allocate by time interval but also to help them decide the types of restrictions that should be placed on reservation requests and how many tables to set aside for walkin and important customer business. Some of the allocation models developed for hotels and airlines, such as bid price models and EMSR-based models could be adapted to the restaurant problem. In addition, overbooking models should be adapted to help restaurants to determine appropriate overbooking levels.

Revenue management holds enormous potential for the restaurant industry. The challenge for researchers is to adapt and develop methods which can be readily applied and accepted by restaurant operators. 